\title{
Neural Networks Applications for Fault Detection on Wind Turbines
}

\author{
R. F. Mesquita Brandão ${ }^{1}$, J. A. Beleza carvalho ${ }^{1}$ and F. P. Maciel Barbosa ${ }^{2}$ \\ ${ }^{1}$ Department of Electrical Engineering \\ ISEP, Oporto Polytechnic Institute \\ Rua Dr António Bernardino de Almeida, 431, 4200-072 Porto (Portugal) \\ Phone:+351 228340 500, e-mail: rfb@isep.ipp.pt, jbc@isep.ipp.pt \\ ${ }^{2}$ FEUP\&INESC Porto, Oporto University \\ Rua Dr Roberto Frias, s/n, 4200-465 Porto (Portugal) \\ Phone:+351 220413 349, e-mail: fmb@fe.up.pt
}

\begin{abstract}
Wind energy is the renewable energy source with a higher growth rate in the last decades. The huge proliferation of wind farms across the world has arisen as an alternative to the traditional power generation and also as a result of economic issues which necessitate monitoring systems in order to optimize availability and profits. Tools to detect the onset of mechanical and electrical faults in wind turbines at a sufficiently early stage are very important for maintenance actions to be well planned, because these actions can reduce the outage time and can prevent bigger faults that may lead to machine stoppage. The set of measurements obtained from the wind turbines is enormous and the use of neural networks may be useful in understanding if there is any important information that may help the prevention of serious failures. The training of the Neural Networks however is not easy because the measurement set used for training must represent a period of time with no faults in the equipment of the turbine that is being monitored.
\end{abstract}

\section{Key words}

Condition Monitoring, Maintenance, Neural Networks, Wind Energy, Wind Turbines.

\section{Introduction}

Wind is nowadays one of the most important sources of energy in the world. From a worldwide viewpoint, installed capacity reached 159213 MW in 2009, out of which, 38312 MW were added in that year, showing a growth rate of $31,7 \%$, the highest since 2001 [1].

In Europe wind has overtaken all other sources of power and has become Europe's number one in terms of new installed capacity and accounted for $39 \%$ of all new power capacity in 2009 [2].

Despite the world financial crisis, wind energy continues to be the most popular renewable power technology in many parts of the world. The reasons for this are climate changes, the will to hedge against volatile fossil fuel prices, speed of deployment and energy security.

An efficient maintenance of wind generators is very important to minimize the operational costs of a modern wind farm.

Table I. - New installed and de-commissioned capacity in EU in 2009 [2]

\begin{tabular}{|c|c|c|}
\hline Source of Energy & $\begin{array}{c}\text { New Capacity } \\
\text { (MW) }\end{array}$ & $\begin{array}{c}\text { De- } \\
\text { commissioned } \\
\text { Capacity (MW) }\end{array}$ \\
\hline Wind & 10163 & 115 \\
\hline Natural Gas & 6630 & 404 \\
\hline PV & 4600 & 0 \\
\hline Coal & 2406 & 3200 \\
\hline Fuel Oil & 573 & 472 \\
\hline Biomass & 581 & 39 \\
\hline Waste & 442 & 24 \\
\hline Nuclear & 439 & 1393 \\
\hline Large Hydro & 338 & 166 \\
\hline CSP & 120 & 0 \\
\hline Small Hydro & 54,5 & 0,6 \\
\hline Other Gas & 12 & 0 \\
\hline Geothermal & 3,9 & 0,5 \\
\hline Ocean & 0,40 & 0 \\
\hline PEAT & 0 & 0 \\
\hline
\end{tabular}

In most of the wind parks covered by the warranty, maintenance is carried out by the wind turbine producer. In the other parks, the wind park owner has his own maintenance teams to do the job or contracts out this specific job. The maintenance is preventive and done in pre-defined periods of time. Normally a minor service is done every 6 months and a major maintenance every 12 months. When the turbine stops or major problems occur, 
maintenance teams are urgently called out to try to solve the fault.

The main objective is to minimize the outage time which in turn implies a maximization of the profits. For these reasons, wind turbine fault detection techniques are becoming indispensable in modern wind parks.

This paper analyses the problem of choosing a data set with quality which can be applied to a Neural Network (NN) with the objective of developing a tool to prevent faults in some wind turbines components.

\section{Measurements}

The application of neural networks (NN) is dependent on the number of measurements and on their quality. The greater the quality data set, the greater the quality the results will be. If a year's measurements are used the data set is very large and can be used for learning, test and validation of the NN. The main goal is to understand which measurements are important to use as input of the $\mathrm{NN}$, because some measurements can have a weak influence on the process and this only contributes to wasting computational time.

One of the great difficulties in training the Neural Network is to find a large period of time where no problems occurred to the equipment that is undergoing monitoring. This period of time will represent the normal behaviour of the equipment. To do this work it is necessary to have information from the maintenance teams about the problems that have arisen in each wind turbine. Depending on which component is being monitored, the measurement set, which is necessary to build the model, is different.

Wind turbines have a lot of sensors measuring important information of its behaviour. Depending on the turbine kind and producer, several measurements are made and saved in the park central computer or in the control centre, if it exists. Measurements are normally 10 minutes average values and can hide important information. In this particular Portuguese wind park equipped with 13 machines of $2 \mathrm{MW}$, measurements saved are:

\author{
Wind speed; \\ Pitch angle; \\ Generator rpm; \\ Power; \\ Frequency; \\ Currents and voltages; \\ 16 wind turbine temperatures.
}

The 16 temperature measurements are very important because they can hide a lot of information about the component's behaviour. For the specific wind turbines in which the study is undergoing, collected temperatures are summarized in Table II, and from those 16 temperature measurements, some of them were used as input of the developed method to prevent faults in the electrical generator of the wind turbine. The method used to choose the most important measurements was based on several aspects that will be briefly explained as follows.
Table II. - Temperatures measurements in the wind turbine.

\begin{tabular}{|c|c|}
\hline & Component \\
\hline Temperature 1 & Environment \\
\hline Temperature 2 & Hydraulics \\
\hline Temperature 3 & Gear Oil \\
\hline Temperature 4 & Generator \\
\hline Temperature 5 & Slip Ring \\
\hline Temperature 6 & Bearing \\
\hline Temperature 7 & Hub Control \\
\hline Temperature 8 & Nacelle \\
\hline Temperature 9 & Top Control \\
\hline Temperature 10 & Busbar \\
\hline Temperature 11 & Spinner \\
\hline Temperature 12 & Transformer L1 \\
\hline Temperature 13 & Transformer L2 \\
\hline Temperature 14 & Transformer L3 \\
\hline Temperature 15 & Generator Bearing \\
\hline Temperature 16 & Cooling Water \\
\hline
\end{tabular}

With the objective of monitoring the electrical generator and to try to prevent faults in the important wind turbine component it was necessary to analyse the behaviour of temperature 4, as shown in table II. Correlation between temperature 4 and all other measurements is an important tool to help choose the most important measurements that may influence the generator temperature. After conducting this analysis it is necessary to understand the behaviour of each correlated measurement as this will prevent the use of measurements that, albeit correlated, do not bring added value to the process. Then it is necessary to check the inertial effect of each selected measurement on the output as sometimes there is an inertial effect in the output in respect to an input and because of this, an alteration in the input may be felt in the variable output for some periods of time afterwards.

By focusing on faults that may arise in the electrical generator, the measurement set was formed by four measurements, which were:

- Average power;

- Average current;

- Temperature 1;

- $\quad$ Temperature 8 .

Note that temperature 1 will suffer a delay of 4 periods of time (t-4) and the average power, average current and temperature 8 will be programmed with a delay of 2 periods of time each $(\mathrm{t}-2)$

The analysis of the delay is based on the cross-correlation between measurements. When two measurements run synchronously the maximum cross-correlation is zero, but if maximum cross-correlation is not zero that means that there is inertia and in those cases it is necessary to introduce a delay in the measurements. Fig. 1 shows an example of a measurement with a lag of 1 period of time, because that is the maximum value of cross-correlations between two measurements. 


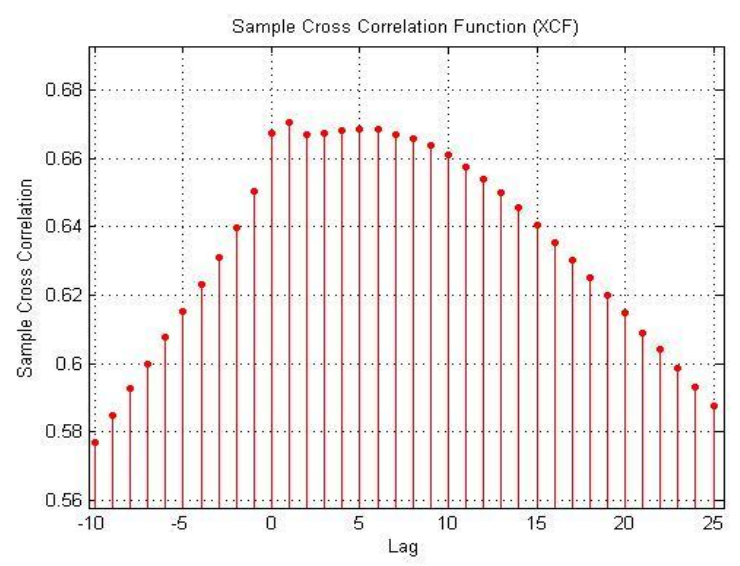

Fig. 1. Cross-correlation between two measurements of a wind turbine.

After defining the most important measurements that need to be used as inputs to the neural network, it is necessary to choose a period of time to train the network.

\section{Neural Network Application}

The main objective of the research work that is presented here is to introduce the problem of using a wrong measurement set to train the neural network and how this poor choice may influence the results of the neural network.

The neural network aims to predict failures in some components of the wind generator. The variable that will be forecasted is the generator temperature (temperature 4) and in order to be able to make this prediction 4 inputs in the input layer will be used alongside 1 hidden layer. An example of the configuration of the neural network is depicted in fig. 2 .

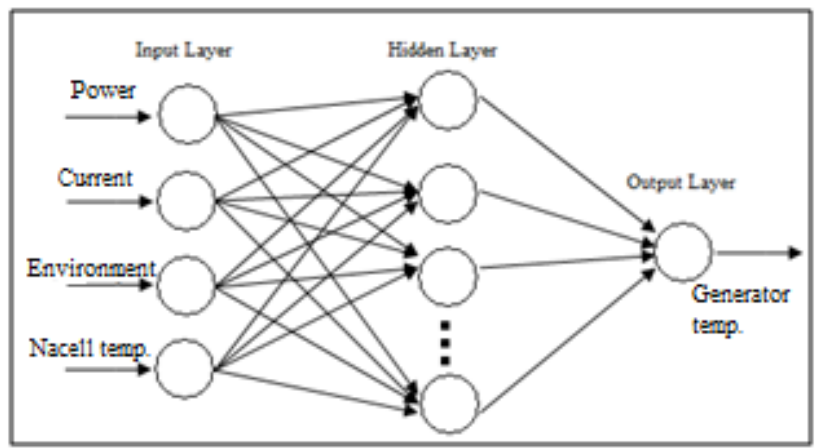

Fig. 2. Schematic of the $\mathrm{NN}$ used to forecast generator temperature.

To develop the model it was necessary to choose the measurement set required to train the neural network. The procedure to select the most important measurements for the train process is not easy because the period of time used to collect the measurements must represent a time of normal behaviour of the turbine with no major problems on the components undergoing monitoring. If the measurement set used to train the $\mathrm{NN}$ contains periods of malfunction of the component under monitoring, all the results can be wrong. To train well the NN, one year of measurements, at least, will be needed. During that period of time, all turbine components must be working well. Any substitution of any equipment results in the necessity of training a new model of the Neural Network, even if the component is substituted by a new one with the same characteristics.

To implement the neural network the CLEMENTINE software and the MATLAB Neural Network toolbox were used. The results obtained by the two software's are similar.

The criterion used to evaluate the model is the Mean Absolute Error (MAE).

$$
M A E=\frac{1}{n} \sum_{i=1}^{n} \sqrt{e_{i}^{2}}
$$

where $e_{i}$ represents the error between the real generator temperature and the estimated one and $n$ is the number of estimations made by the neural network.

A MAE greater than a determined value indicates that something wrong has occurred in the electrical generator.

\section{Experimental Results}

The wind park used to make this study started its activity in 2004 and has 13 wind turbines of $2 \mathrm{MW}$, each equipped with double fed induction generators.

Out of the 13 machines, two of them had problems with the generator machine that led to the substitution of that component due to a winding short circuit. One of those problems occurred in 2005 and the other in 2007. All other wind turbines did not present any serious problems with that component.

By choosing a wind turbine with no problems and observing the results obtained from the developed tool, some conclusions can be drawn.

Table III. - Results of MAE from NN

\begin{tabular}{|c|c|c|}
\hline Month & $\mathbf{2 0 0 7}$ & $\mathbf{2 0 0 8}$ \\
\hline Jan & 4.510 & 6.188 \\
\hline Feb & 6.023 & 6.245 \\
\hline Mar & 4.354 & 6.463 \\
\hline Apr & no data avail. & 7.848 \\
\hline May & 4.327 & 5.05 \\
\hline Jun & 4.325 & 6.749 \\
\hline Jul & 5.586 & 7.187 \\
\hline Aug & 4.852 & 7.690 \\
\hline Sep & 6.004 & 6.144 \\
\hline Oct & 6.248 & 6.337 \\
\hline Nov & 6.451 & 7.329 \\
\hline Dec & 6.745 & 6.85 \\
\hline
\end{tabular}

The ventilation of the nacelle is created by air circulation using electrical ventilators. Some of these ventilators had problems in some wind turbines and for that reason the wind turbine producer decided to substitute that 
component irrespective of it being damaged or not. In September of 2007 the external ventilator of the generator was substituted for a new one. As it is possible to see from table III after September, the MAE value is consistently high. After the substitution of the external component the turbine worked well. Prior to this the turbine was working well too but the simple substitution of a component implies a constant error that can mask other faults or can induce the analysis of the results for a fault ,that in reality, does not exist. To solve this problem it is necessary to create a new model for the neural network, trained with a new measurement set obtained with the new component installed.

Table IV shows clearly that, with a new model created with data obtained after September 2007, the electrical generator of the wind turbine is running well.

Table IV. - Results of MAE from new NN model.

\begin{tabular}{|c|c|c|}
\hline Month & $\mathbf{2 0 0 7}$ & $\mathbf{2 0 0 8}$ \\
\hline Jan & - & 2.892 \\
\hline Feb & - & 3.855 \\
\hline Mar & - & 3.657 \\
\hline Apr & - & $\mathbf{4 . 0 3 9}$ \\
\hline May & - & $\mathbf{4 . 3 5 1}$ \\
\hline Jun & - & 2.678 \\
\hline Jul & - & 2.956 \\
\hline Aug & - & 2.926 \\
\hline Sep & 5.998 & $\mathbf{4 . 1 8 7}$ \\
\hline Oct & 2.826 & 3.77 \\
\hline Nov & 3.046 & $\mathbf{4 . 1 4 4}$ \\
\hline Dec & 3.100 & 3.412 \\
\hline
\end{tabular}

September was the month of the substitution so the MAE for this model is higher denoting that something happened in this month.

The months of 2008 that have higher values of MAE were due to work being carried out in the turbine. In April the gearbox was replaced. May was the month in which major maintenance took place. In September, a maintenance team needed to go to the nacelle to solve some troubles. In November the wind turbine was subjected to minor maintenance.

As you can see from the results presented, this method of fault detection is very sensible and any change in the components that, directly or indirectly, have influence on the measurement used as output by the model, implies the creation of a new model to the turbine.

The acquirement of a good model of the component under monitoring that represents the smooth functioning of that component is not easy in real wind turbines. This is a handicap of the developed method because it is very difficult to have a large period of time with no damage components or with no great actions performed by the maintenance teams on the turbine.
On the other hand, if the measurement set used to train the neural network is not satisfactory, results can be biased and faults can be masked. For all the reasons presented it is important to be especially attentive to the set of measures used to train the neuronal network. It is equally necessary to analyse the measurements and the service reports conducted by the maintenance teams so that the set used for training does not contain measurements obtained in periods where faults in the wind generator have occurred.

\section{Conclusion}

The study presented shows that neural networks are a valid tool and can be useful in making an early detection of failures in some wind turbines equipment. However the neural network training process is the most delicate stage of the developed method. A poorly chosen period of time for the training process will result in a model of neural network that does not translate the correct turbine functioning and hence biased results

All the results presented were applied to the electrical generator of a Portuguese Wind farm but the model can be used for earlier detection of faults in other components of the wind turbine. Similar results were obtained for the detection of gearbox failures.

\section{Acknowledgement}

The first author would like to thank Fundação para a Ciência e Tecnologia, FCT, that partially funded this research work through the $\mathrm{PhD}$ grant $\mathrm{n}$. SFRH/BD/44714/2008.

\section{References}

[1] WWEA (2010 Mar.). World Wind Energy Report 2009. [Online]. Available: http://www.wwinda.org

[2] EWEA (2010 Apr.). 2009 Annual report. [Online]. Available: http://www.ewea.org

[3] P. Caselitz, J. Giebhardt, and M. Mevenkamp, “Applications of condition monitoring systems in wind energy converters," EWEC' 97 Dublin

[4] Mari Cruz Garcia, Miguel A. Sanz-Bobi, and Javier del Pico,"SIMAP: Intelligent system for predictive maintenance application to the health condition monitoring of wind turbine gear box" Computers in Industry, vol. 57, pp. 552568, 2006.

[5] T. J. Hammons, "Renewable Energy, Ed. In-Teh, 2009, pp. 505-530

[6] B. Lu, Y. Li, X. Wu and Z. Yang, "A review of recent advances in wind turbine condition monitoring and fault diagnosis", in Proc. IEEE Conference on Power Electronics and Machines in Wind Applications, 2009, pp. 1-7. 